\title{
The novel bis-benzylisoquinoline PY35 reverses P-glycoprotein-mediated multidrug resistance
}

\author{
ZHONGLIAN CAO ${ }^{1}$, MEREDITH WRIGHT ${ }^{2}$, JIEKAI CHENG $^{3}$, XIAOXING HUANG $^{4}$, \\ $\mathrm{LI} \mathrm{LIU}^{4}$, LIXING WU ${ }^{1}$ and PING YANG ${ }^{1}$ \\ ${ }^{1}$ School of Pharmacy, Fudan University, Shanghai 201203, P.R. China; ${ }^{2}$ Horizon Biopharm, San Jose, CA 95131, USA; \\ ${ }^{3}$ Hangzhou Inspiration Pharmaceutical Development Co., Ltd., Hangzhou, Zhejiang 310030; ${ }^{4}$ Center for Pharmacological \\ Evaluation and Research of SIPI, Shanghai Institute of Pharmaceutical Industry, Shanghai 200437, P.R. China
}

Received April 17, 2014; Accepted June 18, 2014

DOI: $10.3892 /$ or.2014.3326

\begin{abstract}
Multidrug resistance (MDR) to chemotherapeutic drugs is the main cause of chemotherapy failure in cancer treatment, and it generally results from expression of ATP-dependent efflux pump P-glycoprotein (P-gp). MDR reversal agents typically act by inhibiting the drug efflux activity of P-gp, thereby increasing intracellular drug levels. PY35 is a novel 5-substituted tetrandrine (Tet) derivative (CN Application No. 201210238709.6). The present study was performed to investigate the ability of PY35 to reverse P-gp-mediated MDR and its mechanism in resistant K562/Adriamycin (ADM), MCF-7/ADM cells and their sensitive cell lines K562 and MCF-7. The ability of PY35 to reverse drug resistance was evaluated by MTT assay. The results showed that PY35 can reverse MDR more effectively than the drug prototype-Tet. The P-gp function was assessed by the Rhodamine 123 (Rho123; a P-gp substrate) uptake assay with flow cytometry (FCM) and laser scanning confocal microscopes (LSCM); it showed that the MDR cells pumped Rho-123 out the cells, while their sensitive cells scarcely showed efflux. The presence of PY35 efficiently decreased the efflux of the Rho-123, showing that PY35 can reverse P-gp-mediated MDR by increasing the intracellular concentration of Rho-123. The intracellular accumulation of ADM was analyzed by FCM and showed that the coadministration of PY35 and ADM had clearer accumulation than the treatment of Tet and ADM, and was also more evident than treatment with only ADM. The effect of PY35 on the expression of P-gp was assessed by western blotting. The results indicated that PY35 does not inhibit the expression level of the P-gp. This study indicated that PY35 can effectively reverse P-gp-mediated MDR, not by inhibiting the expression of P-gp, but by the coadministration of PY35
\end{abstract}

Correspondence to: Dr Ping Yang, School of Pharmacy, Fudan University, 826 Zhangheng, Pudong, Shanghai 201203, P.R. China E-mail: yangping@fudan.edu.cn

Key words: cancer, multidrug resistance, P-glycoprotein, PY35, adriamycin, rhodamine 123 and ADM that could increase the intracellular accumulation of drugs. Thus, PY35 may be a potential inhibitor to overcome drug resistance.

\section{Introduction}

Chemotherapy is one of the principal modes of treatment for cancer, but the effectiveness of chemotherapy is limited by multidrug resistance (MDR) (1), which generally results from the expression of P-glycoprotein (P-gp), the ATP-dependent efflux pump. MDR reversal agents typically act by inhibiting the drug efflux activity of P-gp, thereby increasing intracellular drug levels. P-gp belongs to a family of ATP-binding cassette $(\mathrm{ABC})$ transporters that have been grouped into seven subfamilies, designated ABCA-ABCG $(2,3)$. ABCB1 encodes P-gp or MDR1, a 170-kDa glycoprotein widely expressed in plasma cell membranes of healthy human tissues and multidrug-resistant tumors $(2,3)$. It has been demonstrated that there is a minimum of four drug binding sites on P-gp. These sites can be divided into two categories: transport sites, at which translocation of drug across the cellular membrane can occur, and regulatory sites, which modify $\mathrm{P}$-gp function. In addition, some agents can inhibit P-gp activity by decreasing intracellular ATP supply and inhibiting P-gp ATPase activity $(4,5)$. To overcome the clinical problem of P-gp-mediated MDR, several generations pharmacological inhibitors of P-gp have been developed (6). The first-generation inhibitors such as verapamil (the calcium channel blockers) and the immunosuppressant cyclosporin, reverse MDR by functioning as competitive substrates of P-gp (7), but they display low binding affinity to $\mathrm{P}-\mathrm{gp}$, thus precluding further investigation after phase I clinical trials (8). The second-generation agents are analogues of the first generation drugs (e.g. dexverapamil, valspodar and cinchonine) with supposedly higher selectivity and activity; however, there are several factors that limit their clinical use (9), including that they are often inhibitors of other ABC transporters as well (10-12). Another factor is that they may be substrates of cytochrome P-450 (CYP), resulting in pharmacokinetic interactions with increased host toxicity from cytotoxic drug overexposure (13-16). The third-generation agents are potentially able to overcome the limitations of previous generation compounds $(8,10,17-19)$; they are not 
substrates of P-gp, they act through noncompetitive inhibition of the pump, and bind with high affinity to it $(20,21)$. Several P-gp inhibitors have been tested in controlled clinical trials; however, due to the cytotoxicity, no satisfactory results have thus far been obtained $(3,22)$.

Many studies have focused on the Chinese traditional medicine Tetrandrine (Tet), a bis-benzylisoquinoline alkaloid derived from the Chinese medicinal herb Stephania tetrandra (23). It is a voltage-activated, L-type $\mathrm{Ca}^{2+}$ channel with its binding site at the benzothiazepine receptor on the $\alpha 1$-subunit and it also blocks the voltage-dependent T-type $\mathrm{Ca}^{2+}$ channel (24). Tet has been used in the treatment of hypertension, cardiac arrhythmia and angina pectoris in China since the 1950s (24). A previous study showed that Tet can reverse P-gp-mediated MDR effectively in vitro and in vivo (25). A series of new bisbenzylisoquinoline alkaloids is partially synthesized from Tet, and evaluated for their ability to reverse P-gp-mediated MDR in cancer. PY35 is a novel 5-substituted Tet derivative, synthesized by us. In the current study, the reversal activity of PY35 on MDR was examined, and it showed that PY35 reverses the P-gp-mediated MDR in cancer cells, increases the accumulation of cytotoxic agents in multidrug-resistant MCF-7/ADM and K562/ADM cells, but it has no effect on $\mathrm{P}$-gp expression. Therefore, the combination of PY35 with a cytotoxic agent may help overcome MDR in the clinic.

\section{Materials and methods}

Chemicals and reagents. Adriamycin (ADM), trypsin-EDTA solution, fetal bovine serum (FBS), MTT (tetrazolium), Rhodamine-123 (Rho-123), DAPI, P-gp and GAPDH mouse anti-human monoclonal antibody and HRP-linked secondary antibody were obtained from Sigma Chemical (St. Louis, MO, USA). RPMI-1640 was purchased from Gibco-BRL. Tetrandrine (Tet) was a gift from Dr Jiekai Cheng, and PY35 with a purity of $>98 \%$ was synthesized by our lab. Both were evaluated by chromatography, HRMS-ESI (Figs. 1 and 2, Table I) and NMR.

Cell culture. Drug sensitive human breast carcinoma and MCF-7 and human leukemia cell line K562 and their MDR sublines MCF-7/ADM and K562/ADM were cultured in RPMI-1640 medium with $10 \%$ newborn bovine serum, $100 \mathrm{U} / \mathrm{ml}$ penicillin, and $100 \mu \mathrm{g} / \mathrm{ml}$ streptomycin at $37^{\circ} \mathrm{C}$ in a humidified atmosphere of $5 \% \mathrm{CO}_{2}$. To maintain MDR phenotype, MCF-7/ADM and K562/ADM cells were cultured in the medium containing $1 \mu \mathrm{g} / \mathrm{ml} \mathrm{ADM}$ at least 1 week before the experiments.

MTT cytotoxicityassay. The cytotoxicity of PY 35 was measured by the MTT assay. Tumor cells were seeded in 96-well plates in $100 \mu \mathrm{l}$ medium per well and attached overnight. A series of concentrations of PY35 were added to each well and incubated for 2 days at $37^{\circ} \mathrm{C}$, then the $100 \mu \mathrm{l}$ of MTT were added to each well after removing the culture medium and then incubated for an additional $4 \mathrm{~h}$. The formed formazan was dissolved in $150 \mu \mathrm{l}$ DMSO after removing the culture medium. The plates were shaken for $5 \mathrm{~min}$ and the optical density was measured by the microplate reader (Tecan M1000) at a wavelength of $570 \mathrm{~nm}$. The $\mathrm{IC}_{50}$ values were calculated by Graphpad Prism 6.0 software. According to the results of the cytotoxicity assay,

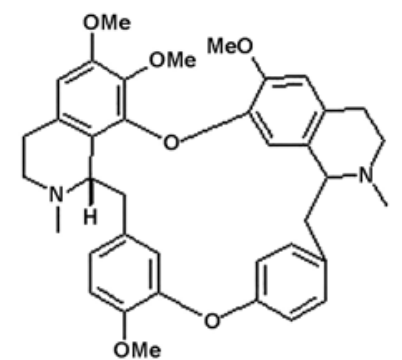

Tet

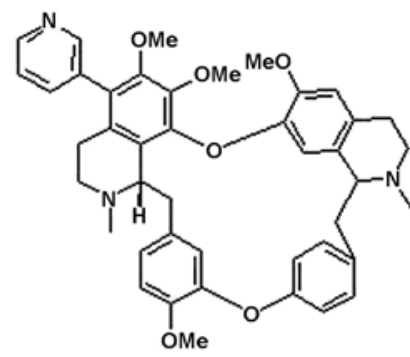

PY35
Figure 1. The molecular structure of Tet and PY35.
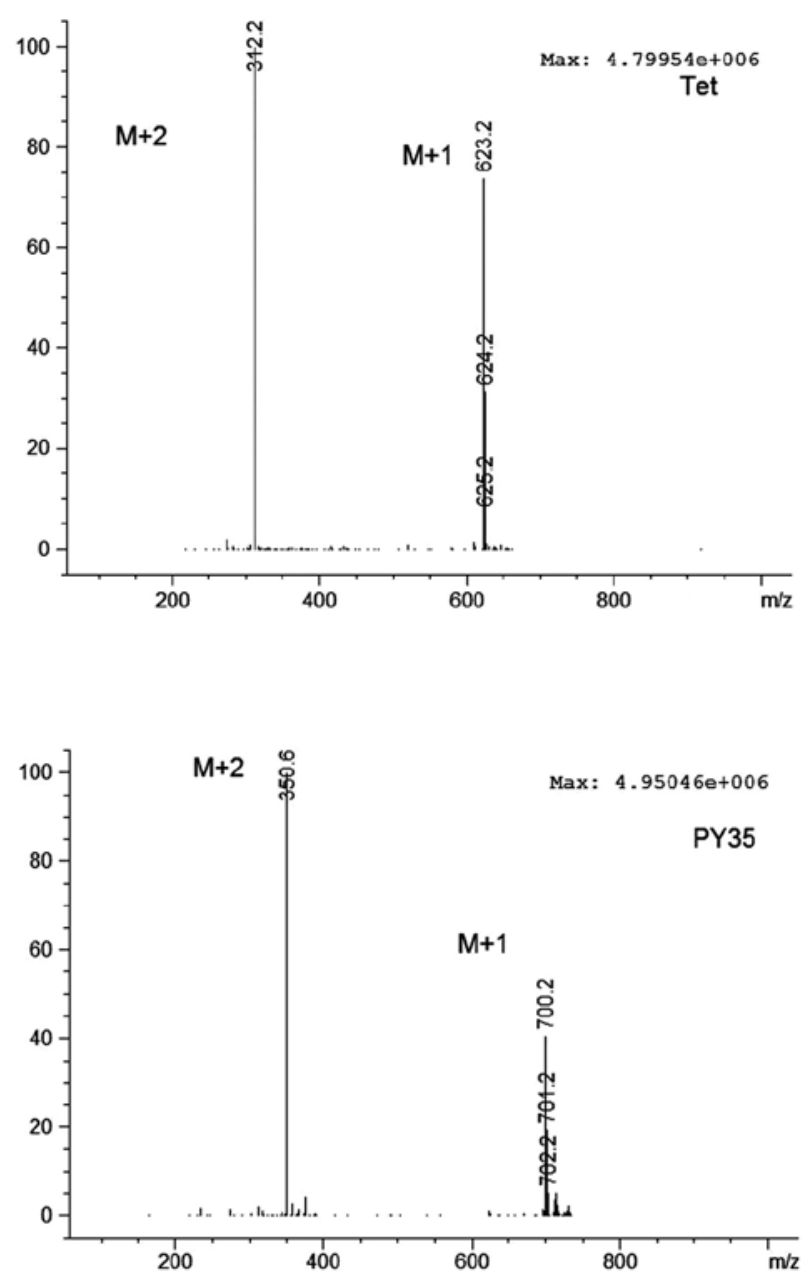

Figure 2. The MS Spectrum of Tet and PY35.

cytotoxic concentrations of PY35 were selected to determine the reverse MDR effect. The reversal activity of PY35 on drug resistance is expressed as the fold reversal calculated according to the following equation: $\mathrm{RVF}=\mathrm{IC}_{50}$ anticancer drug alone/ $\mathrm{IC}_{50}$ anticancer drug + inhibitor. Tet was used as a control.

Rho-123 uptake assays. The assay was performed according to a previous method (26). For the Rho-123 uptake assay, cells were incubated with $5 \mu \mathrm{M}$ Rho-123, in the presence or absence of PY35, at $37^{\circ} \mathrm{C}$ for $1 \mathrm{~h}$. The cells were observed under a laser scanning confocal microscope (LSCM, Zeiss 
Table I. The HRMS data of Tet and PY35.

\begin{tabular}{|c|c|c|c|c|c|}
\hline Compound name & Formula & $\begin{array}{c}\text { Expected } \\
\mathrm{m} / \mathrm{z}\end{array}$ & $\begin{array}{c}\text { Found at } \\
\mathrm{m} / \mathrm{z}\end{array}$ & $\begin{array}{l}\text { Isotope diff. } \\
(\%)\end{array}$ & $\begin{array}{l}\text { Error } \\
(\mathrm{ppm})\end{array}$ \\
\hline Tet & $\mathrm{C} 38 \mathrm{H} 42 \mathrm{~N} 2 \mathrm{O} 6$ & 623.3116 & 623.3113 & 4.4 & -0.4 \\
\hline PY35 & $\mathrm{C} 43 \mathrm{H} 45 \mathrm{~N} 3 \mathrm{O} 6$ & 700.3381 & 700.3383 & 1.5 & 0.2 \\
\hline
\end{tabular}
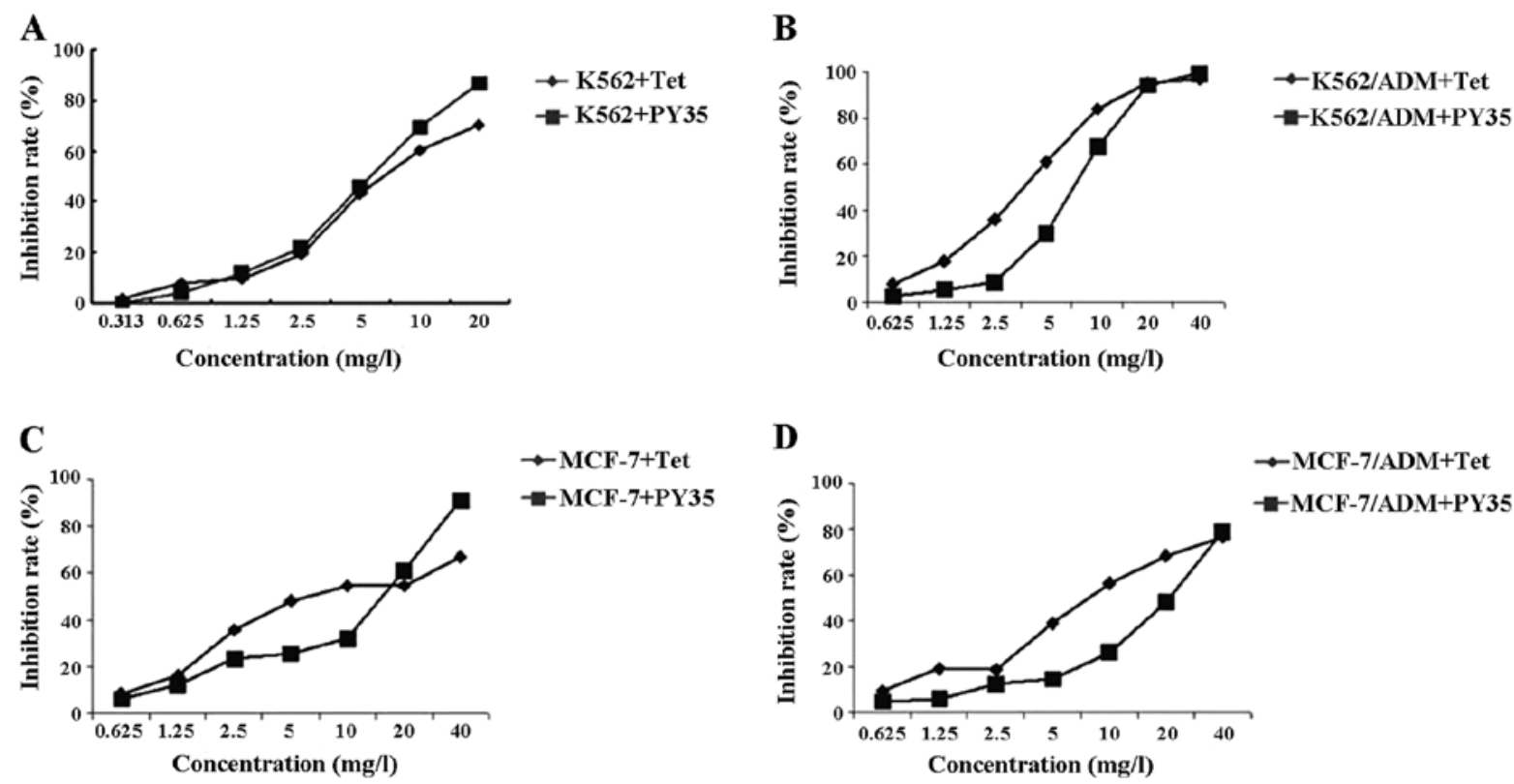

Figure 3. The cytotoxicity of PY35 to tumor cell lines K562 (A), K562/ADM (B), MCF-7 (C) and MCF-7/ADM (D) assessed by the MTT assay. Cells were treated with different concentrations of PY35 for $48 \mathrm{~h}$.

LSM 710, Germany) and analyzed with flow cytometry (FCM) (FACSAria; BD Biosciences, Franklin Lakes, NJ, USA).

Intracellular accumulation of ADM. Intracellular accumulation of ADM was detected by FCM. The K562/ADM and MCF-7/ADM cells were treated as previously described. After being cultured for $48 \mathrm{~h}$, cells were washed three times with phosphate-buffered saline (PBS) and then suspended with $500 \mu 1$ of PBS. Thereafter, each sample was measured by FCM at excitation/emission wavelengths of $488 / 575 \mathrm{~nm}$. The mean fluorescence intensity (MFI) of ADM was calculated as MFI treated group/MFI control group.

Western blotting. Following drug treatment, cells were washed three times with ice-cold PBS, and total cells were lysed, total protein was collected and was separated by SDS-PAGE and transferred to polyvinylidine difluoride membranes. After blocking in 5\% non-fat milk in Tris-buffered saline with $0.1 \%$ Tween-20 (pH 7.6), mouse anti-human P-gp monoclonal antibody and mouse anti-human GAPDH monoclonal antibody were used as primary antibodies and HRP-linked secondary antibody were used to detect P-gp protein.

Statistical analysis. Data are expressed as the means \pm SD. Statistical analysis of the data was performed using the Student's t-test. $\mathrm{P}<0.05$ was considered statistically significant.
Table II. Effect of PY35 on the cytotoxicity of ADM (expressed as $\mathrm{IC}_{50}$ values).

\begin{tabular}{lccccc}
\hline & \multicolumn{4}{c}{ Cell lines } \\
\cline { 2 - 3 } \cline { 5 - 6 } \cline { 5 - 6 } Groups & \multicolumn{2}{c}{$\mathrm{K} 562 / \mathrm{ADM}$} & & $\mathrm{MCF}-7 / \mathrm{ADM}$ \\
\cline { 2 - 3 } \cline { 5 - 6 } ADM & $\mathrm{IC}_{50}(\mu \mathrm{g} / \mathrm{ml})$ & $\mathrm{RVF}$ & & $\mathrm{IC}_{50}(\mu \mathrm{g} / \mathrm{ml})$ & $\mathrm{RVF}$ \\
ADM+Tet & $13.00 \pm 0.86^{\mathrm{a}}$ & 5.24 & & $4.92 \pm 0.45^{\mathrm{c}}$ & 22.91 \\
ADM+PY35 & $2.34 \pm 0.53^{\mathrm{b}}$ & 29.14 & & $2.98 \pm 0.47^{\mathrm{c}}$ & 37.83 \\
\hline
\end{tabular}

Tumor cells were treated with graded concentrations of ADM in the absence or presence of PY35. After $48 \mathrm{~h}$ of continuous drug exposure, the cell survival rate was measured by MTT assay. The data presented are the mean $\pm \mathrm{SD}$. $\mathrm{IC}_{50}$ values from at least three independent experiments. $\mathrm{RVF}=\mathrm{IC}_{50}$ anticancer drug alone $/ \mathrm{IC}_{50}$ anticancer drug + inhibitor. ${ }^{\mathrm{a}} \mathrm{P}<0.05,{ }^{\mathrm{b}} \mathrm{P}<0.01$ vs. K562/ADM+ADM; ${ }^{\mathrm{C}} \mathrm{P}<0.05$ vs. MCF-7/ADM+ADM, $\mathrm{n}=3$.

\section{Results}

Evaluation of the cytotoxic effect of PY35. As shown in Fig. 3, $>90 \%$ cells survived at the concentrations of $0.625 \mu \mathrm{g} / \mathrm{ml}$ PY35 on these cell lines. Based on the results of the cytotox- 


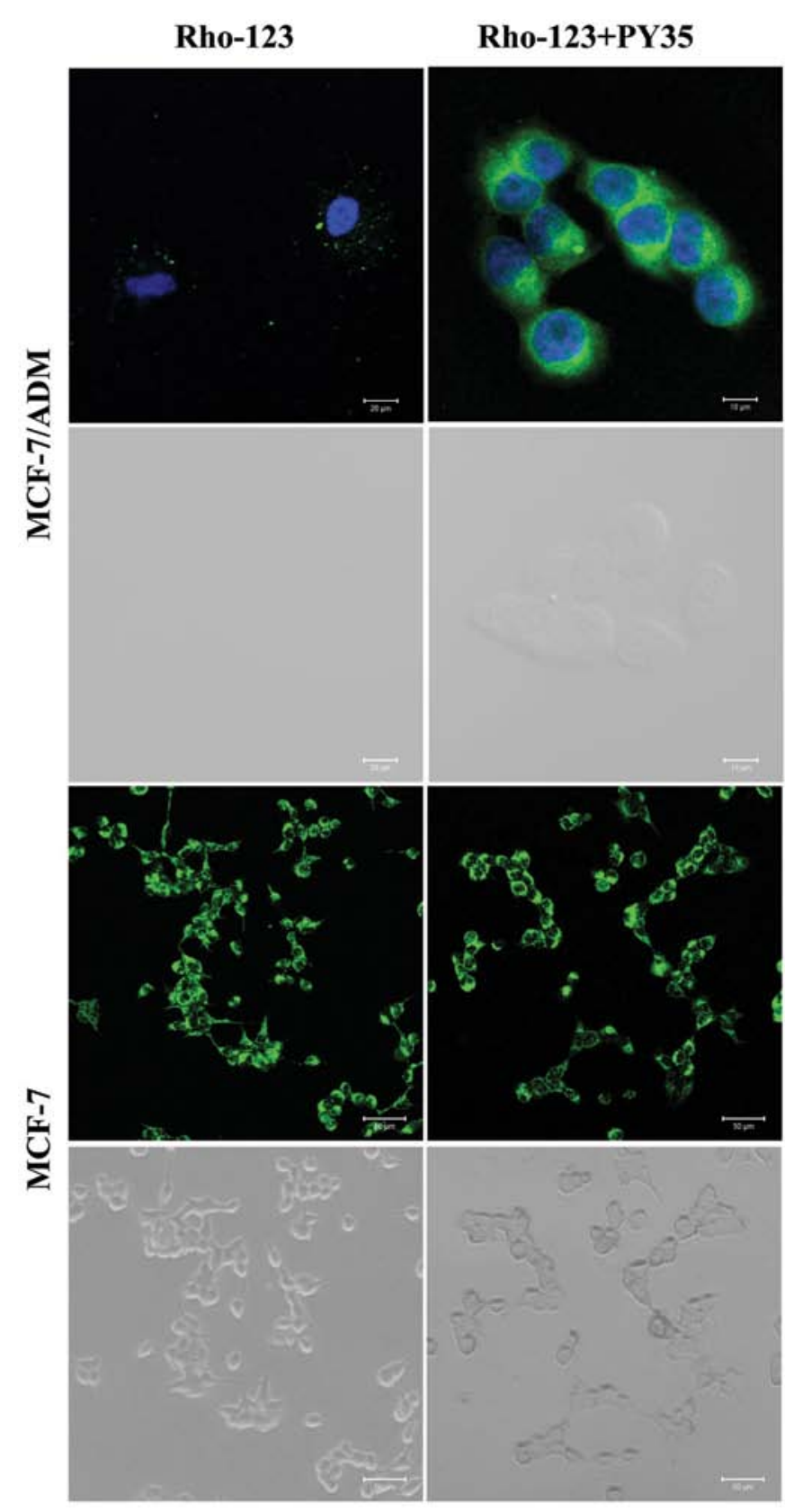

Figure 4. MCF-7 and MCF-7/ADM cells were incubated with $5 \mu \mathrm{M}$ Rho-123 in the absence or presence of PY35. The cells were observed under the LSCM. PY35 had an evident effect on the Rho-123 uptake in MCF-7/ADM cells, but it had no evident effect in MCF-7 cells.

icity assay above, we used $0.625 \mu \mathrm{g} / \mathrm{ml}$ PY35 to evaluate the reversal activity.

PY35 reverses MDR. The $\mathrm{IC}_{50}$ of ADM for K562, K562/ADM, MCF-7 and MCF-7/ADM cells were 0.45, 68.12, 4.50 and $112.72 \mu \mathrm{g} / \mathrm{ml}$ respectively. The multiple of drug resistance was 149.95 and 25.05. After the K562/ADM cells and MCF-7/ADM cells were treated with PY35 alone or in combination, $\mathrm{IC}_{50}$ was 2.34 and $2.98 \mu \mathrm{g} / \mathrm{ml}$, respectively. The reversal multiples were 29.14 and 37.83 , respectively. Between the single agent treatment groups and the combined treatment groups, the differences were statistically significant $(\mathrm{P}<0.05)$ (Table II).
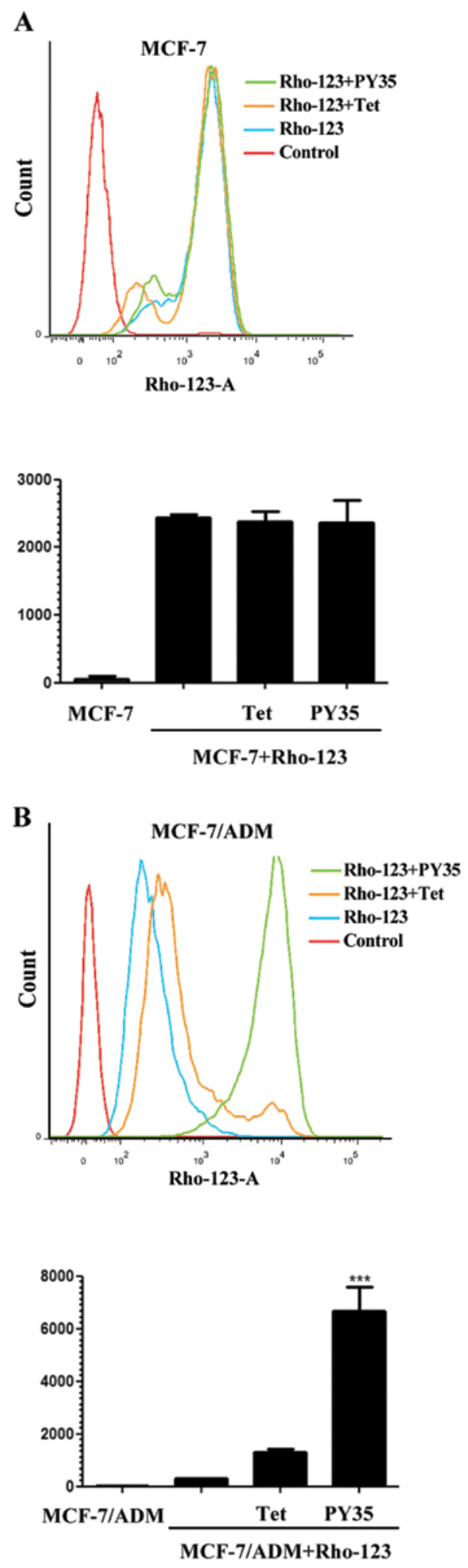

Figure 5. Uptake of Rho-123 in multidrug-resistant MCF-7/ADM cells and their sensitive parent MCF-7 cell lines analyzed by FCM. PY35 had an evident effect on the Rho-123 uptake in MCF-7/ADM cells, but it had no evident effect in MCF-7 cells.

Rho-123 uptake assays. The intracellular uptake of the fluorescent dye Rho-123 was evaluated in two MDR cell lines and their sensitive counterparts by using FCM and LSCM. After incubation with Rho-123 for $1 \mathrm{~h}$, the addition of PY35 led to significantly increased intracellular Rho-123 levels in the 


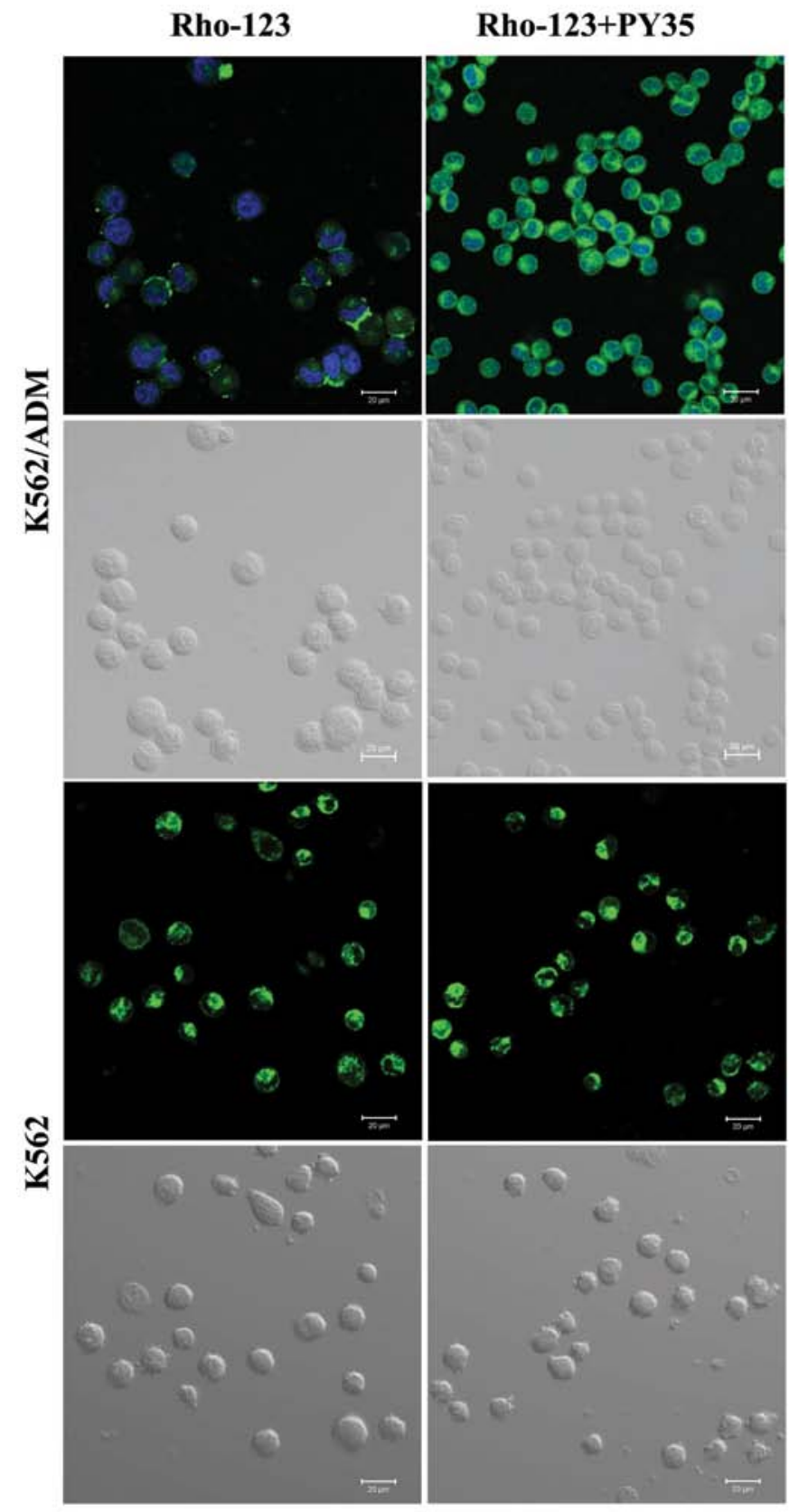

Figure 6. K562 and K562/ADM cells were incubated with $5 \mu$ M Rho-123 in the absence or presence of PY35. The cells were observed under the LSCM. PY35 had an evident effect on the Rho-123 uptake in K562/ADM cells, but it had no evident effect in K562 cells.

resistant but not sensitive cells. The results indicated that the amount of Rho-123 accumulation in cells treated with PY35 plus Rho-123 was significantly higher than that in cells treated with Rho-123 alone and control cells (Figs. 4-7).

Effect of PY35 on cellular accumulation of ADM. The MFI of ADM in K562/ADM cells and MCF-7/ADM cells incubated with ADM, ADM+PY35 respectively were 13.86 \pm 1.21 , $146.78 \pm 10.25,12.35 \pm 1.58$, and $67.34 \pm 5.34$, respectively. Compared with the ADM group, the ADM+PY35 group significantly enhanced the intracellular ADM accumulation (Fig. 8).
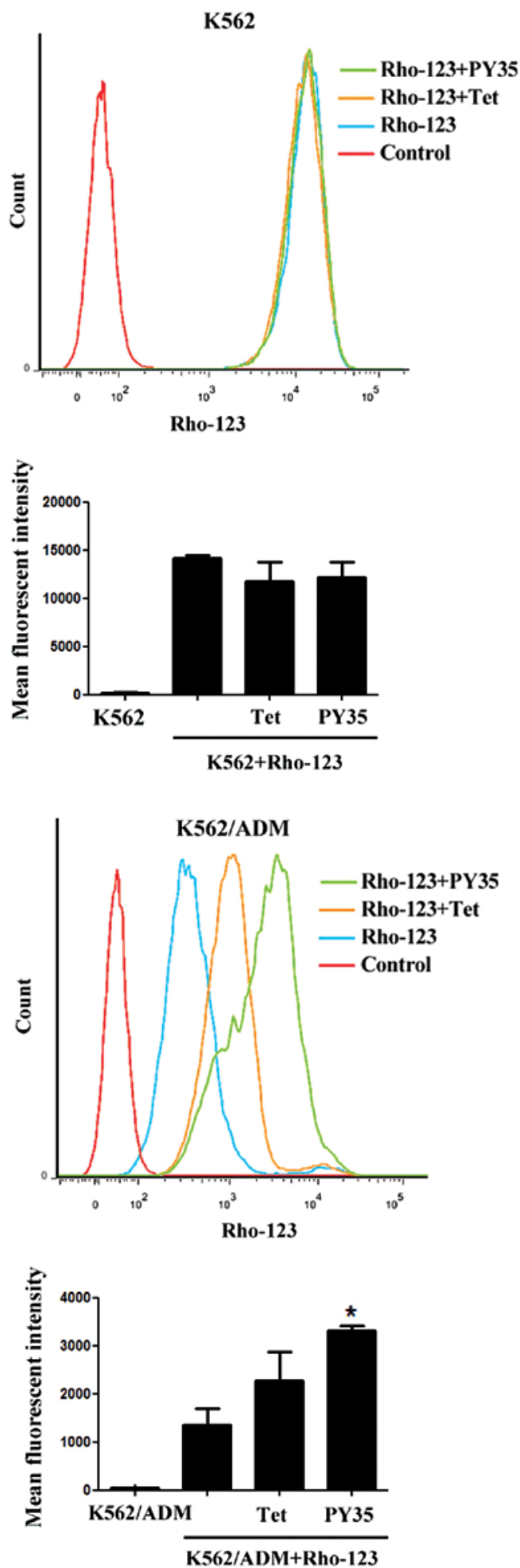

Figure 7. Uptake of Rho-123 in multidrug-resistant K562/ADM cells and their sensitive parent K562 cell lines analyzed by FCM. PY35 had an evident effect on the Rho-123 uptake in K562/ADM cells, but it had no evident effect in K562 cells.

PY35 does not affect P-gp expression. To further investigate the MDR reversal mechanism of PY35, we analyzed P-gp expression in K562/ADM and MCF-7/ADM cells after they were treated with PY35 by western blotting; the expression levels of P-gp were not affected by PY35 (Fig. 9A and B). 
A
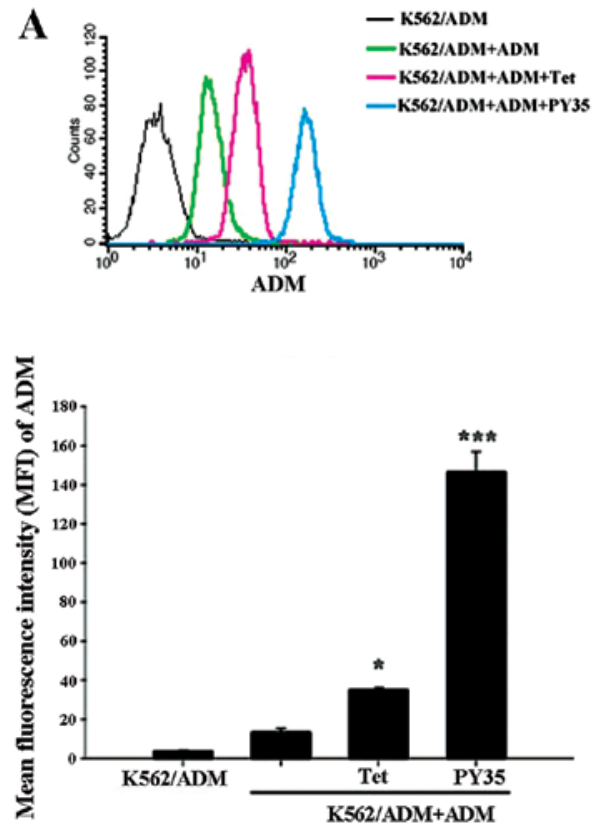
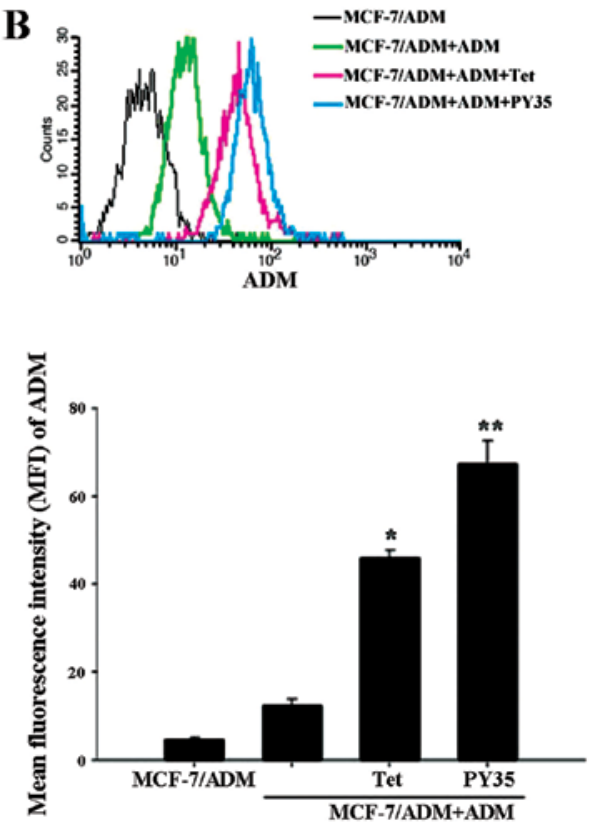

Figure 8. Intracellular accumulation of ADM in K562/ADM (A) and MCF-7/ADM (B) cells, incubated for 48 h by FCM assay. ${ }^{*} \mathrm{P}<0.05,{ }^{* * *} \mathrm{P}<0.01,{ }^{* * * *} \mathrm{P}<0.001$ vs. K562/ADM+ADM, MCF-7/ADM+ADM.

A
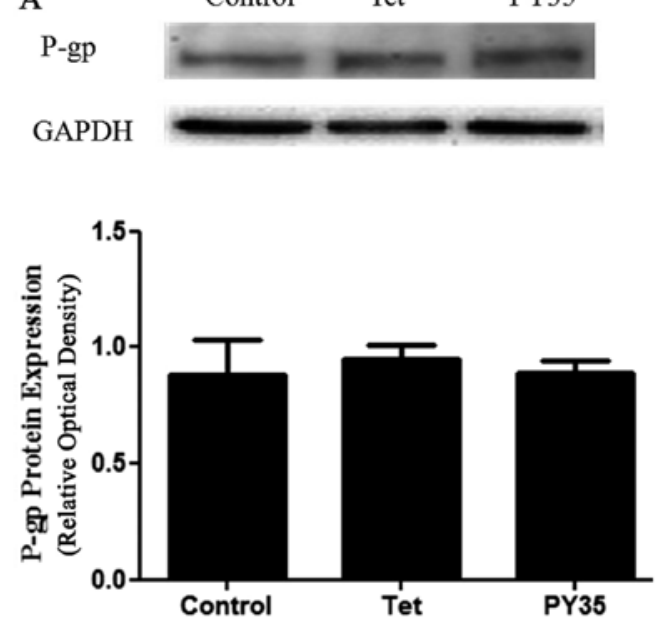

B

P-gp

GAPDH

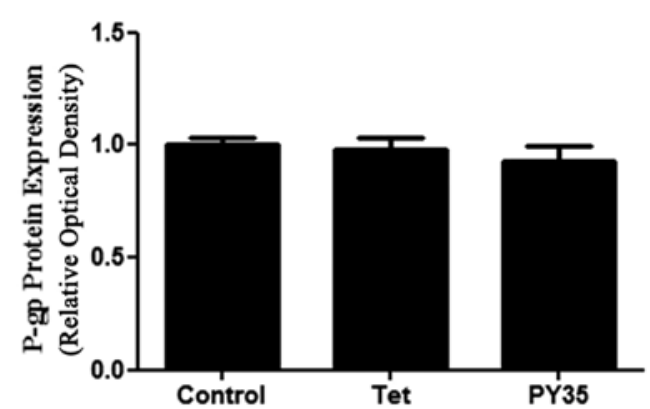

Figure 9. The effect of PY35 on P-gp expression in (A) MCF-7/ADM cells and (B) K562/ADM cells. P-gp expression detected by western blotting. After K562/ ADM and MCF-7/ADM cells were exposed to PY35 for $48 \mathrm{~h}$, the protein was extracted and analyzed by western blotting. The results showed PY35 did not affect the expression of P-gp in K562/ADM and MCF-7/ADM cells.

\section{Discussion}

Multidrug resistance (MDR) remains a major impediment to successful chemotherapy. To overcome MDR, a wide series of compounds have been studied as P-gp inhibitors and some are undergoing clinical trials, although most have been stopped due to toxicity.

Tetrandrine (Tet) is a benzylisoquinoline alkaloid and studies have shown that it has a reversal effect on P-gpmediated MDR $(2,3)$. It is an extremely potent MDR inhibitor both in vitro and in vivo, without apparently enhancing the toxicity of the coadministered drugs (27). PY35 is a novel 5 -substituted Tet derivative and this study showed that its reversal activity was higher than the Tet; the reversal multiples of PY35 were 29.14 in K562/ADM and 37.83 in MCF-7/ADM, while the reversal multiples of Tet were 5.24 in K562/ADM and 22.91 in MCF-7/ADM respectively.

The P-gp functional activity was investigated with Rho-123. Rho-123 is a fluorescence substrate that is applied to investigate $\mathrm{P}$-gp functional activity and is a sensitive measure of MDR (28). When P-gp functional activity decreased, the accumulation of the Rho-123 substrate within cells increased and vice versa. The intracellular uptake of the fluorescent dye Rho-123 was evaluated in two MDR cell lines and their sensitive counterparts by using FCM and LSCM. After incubation with Rho-123 for $1 \mathrm{~h}$, the presence of PY35 led to significantly increased intracellular Rho-123 levels in the resistant but not sensitive cells. This demonstrates that PY35 can reverse P-gpmediated MDR by increasing the intracellular concentration of Rho-123. 
In the present study, the ADM accumulation assay was used to evaluate the inhibitory effect of PY35 on P-gp in K562/ADM and MCF-7/ADM cell lines. The results showed that the accumulation in the cells treated with ADM and PY35 was significantly higher than in the cells treated with ADM alone. The ADM accumulation treated with PY35 was more compared to Tet, confirming that PY35 could effectively inhibit the drug efflux compared to Tet (Fig. 8).

$\mathrm{P}$-gp expression and activity of $\mathrm{P}$-gp were generally viewed as the functional difference between resistant cells and their sensitive parent cell lines. Western blot analysis showed that the expression levels of P-gp in resistant cells treated with Tet and PY35 had no statistical significance in terms of relative gray-scale value (Figs. 9). The expression levels of P-gp were not affected by the treatment with PY35.

In conclusion, in vitro findings indicated that the MDR reversal activity of PY35 was very high; it could reverse P-gp-mediated MDR and the coadministration of PY35 and a cytotoxic agent could increase the intracellular accumulation of drugs. These findings confirm PY35 as a potential inhibitor to overcome MDR, exhibiting clinical benefits in cancer treatment.

Our current hypothesis is that PY35 overcomes drug resistance by blocking the calcium channel, leading to the concentration of $\mathrm{Ca}^{2+}$ decreases in cells, then the ATP production declines, thus the ATP-dependent P-gp efflux less chemotherapeutic drugs. Further studies are required to confirm the relationship between these pharmaceutical actions, which merits further attention.

\section{References}

1. Holohan C, Van Schaeybroeck S, Longley DB and Johnston PG: Cancer drug resistance: an evolving paradigm. Nat Rev Cancer 13: 714-726, 2013

2. Gottesman MM: Mechanisms of cancer drug resistance. Annu Rev Med 53: 615-627, 2002.

3. Szakacs G, Paterson JK, Ludwig JA, Booth-Genthe C and Gottesman MM: Targeting multidrug resistance in cancer. Nat Rev Drug Discov 5: 219-234, 2006.

4. Batrakova EV, Li S, Elmquist WF, Miller DW, Alakhov VY and Kabanov AV: Mechanism of sensitization of MDR cancer cells by Pluronic block copolymers: selective energy depletion. Br J Cancer 85: 1987-1997, 2001.

5. Batrakova EV, Li S, Vinogradov SV, Alakhov VY, Miller DW and Kabanov AV: Mechanism of pluronic effect on P-glycoprotein efflux system in blood-brain barrier: contributions of energy depletion and membrane fluidization. J Pharmacol Exp Ther 299 483-493, 2001.

6. Woodhouse JR and Ferry DR: The genetic basis of resistance to cancer chemotherapy. Ann Med 27: 157-167, 1995.

7. Wigler PW: Cellular drug efflux and reversal therapy of cancer. J Bioenerg Biomembr 28: 279-284, 1996.

8. Robert J and Jarry C: Multidrug resistance reversal agents. J Med Chem 46: 4805-4817, 2003.

9. Nobili S, Landini I, Mazzei T and Mini E: Overcoming tumor multidrug resistance using drugs able to evade P-glycoprotein or to exploit its expression. Med Res Rev 32: 1220-1262, 2012.
10. Krishna $\mathrm{R}$ and Mayer LD: Multidrug resistance (MDR) in cancer. Mechanisms, reversal using modulators of MDR and the role of MDR modulators in influencing the pharmacokinetics of anticancer drugs. Eur J Pharm Sci 11: 265-283, 2000.

11. Böhme M, Büchler M, Müller M and Keppler D: Differential inhibition by cyclosporins of primary-active ATP-dependent transporters in the hepatocyte canalicular membrane. FEBS Lett 333: 193-196, 1993.

12. Song S, Suzuki H, Kawai R, Tanaka C, Akasaka I and Sugiyama Y: Dose-dependent effects of PSC 833 on its tissue distribution and on the biliary excretion of endogenous substrates in rats. Drug Metab Dispos 26: 1128-1133, 1998.

13. Wandel C, Kim RB, Kajiji S, Guengerich P, Wilkinson GR and Wood AJ: P-glycoprotein and cytochrome P-450 3A inhibition: dissociation of inhibitory potencies. Cancer Res 59: 3944-3948, 1999.

14. Bates S, Kang M, Meadows B, et al: A Phase I study of infusional vinblastine in combination with the P-glycoprotein antagonist PSC 833 (valspodar). Cancer 92: 1577-1590, 2001.

15. Fischer V, Rodriguez-Gascon A, Heitz F, et al: The multidrug resistance modulator valspodar (PSC 833) is metabolized by human cytochrome P450 3A. Implications for drug-drug interactions and pharmacological activity of the main metabolite. Drug Metab Dispos 26: 802-811, 1998.

16. Kang MH, Figg WD, Ando Y, et al: The P-glycoprotein antagonist PSC 833 increases the plasma concentrations of 6alpha-hydroxypaclitaxel, a major metabolite of paclitaxel. Clin Cancer Res 7: 1610-1617, 2001.

17. Mayur YC, Peters GJ, Prasad VV, Lemo C and Sathish NK: Design of new drug molecules to be used in reversing multidrug resistance in cancer cells. Curr Cancer Drug Targets 9: 298-306, 2009.

18. Martelli C, Alderighi D, Coronnello M, et al: N,N-bis(cyclohexanol)amine aryl esters: a new class of highly potent transporter-dependent multidrug resistance inhibitors. J Med Chem 52: 807-817, 2009.

19. Teodori E, Dei S, Martelli C and Scapecchi S: N,N-bis(cyclohexanol)amine aryl esters: the discovery of a new class of highly potent inhibitors of transporter-dependent multidrug resistance (MDR). Curr Top Med Chem 10: 1715-1731, 2010.

20. Yang $\mathrm{K}, \mathrm{Wu} \mathrm{J}$ and $\mathrm{Li} \mathrm{X}$ : Recent advances in the research of P-glycoprotein inhibitors. Biosci Trends 2: 137-146, 2008.

21. Thomas $\mathrm{H}$ and Coley HM: Overcoming multidrug resistance in cancer: an update on the clinical strategy of inhibiting P-glycoprotein. Cancer Control 10: 159-165, 2003.

22. Fletcher JI, Haber M, Henderson MJ and Norris MD: ABC transporters in cancer: more than just drug efflux pumps. Nat Rev Cancer 10: 147-156, 2010.

23. King VF, Garcia ML, Himmel D, et al: Interaction of tetrandrine with slowly inactivating calcium channels. Characterization of calcium channel modulation by an alkaloid of Chinese medicinal herb origin. J Biol Chem 263: 2238-2244, 1988.

24. Wang G and Lemos JR: Tetrandrine: a new ligand to block voltage-dependent $\mathrm{Ca}(2+)$ and $\mathrm{Ca}(+)$-activated $\mathrm{K}(+)$ channels. Life Sci 56: 295-306, 1995.

25. Chen YJ: Potential role of tetrandrine in cancer therapy. Acta Pharmacol Sin 23: 1102-1106, 2002.

26. Ludescher C, Gattringer, Drach J, Hofmann J and Grunicke H: Rapid functional assay for the detection of multidrug-resistant cells using the fluorescent dye rhodamine 123. Blood 78: 1385-1387, 1991

27. Fu LW, Zhang YM, Liang YJ, Yang XP and Pan QC: The multidrug resistance of tumour cells was reversed by tetrandrine in vitro and in xenografts derived from human breast adenocarcinoma MCF-7/adr cells. Eur J Cancer 38: 418-426, 2002.

28. Mosmann T: Rapid colorimetric assay for cellular growth and survival: application to proliferation and cytotoxicity assays. J Immunol Methods 65: 55-63, 1983. 